\title{
Historic range of variability of mountain forest ecosystems: concepts and applications ${ }^{1}$
}

\author{
by Thomas T. Veblen ${ }^{2}$
}

Concepts of historical range of variability (HRV) have taken on an increasingly important role in resource planning and the management of mountain forest ecosystems. This essay draws on examples from the study of the history of disturbance ecology in the Colorado Rocky Mountains and the southern Andes to examine key HRV concepts and their applications. These case studies show that historical perspectives can reduce the chances of major future surprises in ecosystem conditions related to climatic variation, which often overrides many of the effects of management practices. They demonstrate the long-lasting legacy effects of relatively infrequent but severe disturbances in the past that shaped the present landscape and its potential response to future climatic variation. Finally, the case studies illustrate the importance of conducting area-specific research in potential management areas rather than simply extrapolating research findings from studies of historic range of variability of forest ecosystems conducted elsewhere.

Keywords: climatic variation, disturbance, Rocky Mountains, Andes, Patagonia, Ponderosa pine, landscape, ecosystem management, fire

Les concepts de la distribution historique de la variabilité (DHV) ont accaparé un rôle de plus en plus important dans la planification des ressources et l'aménagement des écosystèmes des forêts montagneuses. Cet essai tire des exemples de l'étude de l'histoire de l'écologie de perturbation dans les Montagnes Rocheuses du Colorado et du sud des Andes dans le but d'examiner les principaux concepts de DVH et leurs applications. Ces études de cas indiquent que les perspectives historiques peuvent réduire les chances d'avoir d'importantes surprises futures dans le cas de conditions écosystémiques reliées aux variations climatiques, qui souvent, annulent plusieurs effets des pratiques d'aménagement. Elles soulignent les effets engendrés à long terme des perturbations relativement peu fréquentes mais sévères survenues dans le passé et qui façonnent le paysage actuel, ainsi que les réactions potentielles aux variations climatiques futures. Finalement, les études de cas illustrent l'importance de mener des recherches spécifiques dans des domaines potentiels d'aménagement pour une zone donnée, plutôt que de simplement extrapoler les résultats de recherche provenant d'études de la variabilité historique des écosystèmes forestiers entreprises ailleurs.

Mots-clés : variation climatique, Montagnes Rocheuses, Andes, Patagonie, pin Ponderosa, paysage, aménagement écosystémique, feu

\section{Introduction}

Knowledge of the historic range of variability (HRV) of mountain forest ecosystems can play a key role in resource planning and management decisions. The emerging scientific and management paradigm of ecosystem-based management (Christensen et al. 1996) has been defined as: Management driven by explicit goals, executed by policies, protocols, and practices, and made adaptable by monitoring and research based on our best understanding of the ecological interactions and processes necessary to sustain ecosystem structure and function. A critical component of the ecosystem management paradigm is explicit recognition of the dynamic character of ecosystems in relation to natural and anthropogenic disturbances as well as climatic variation. For resource managers, it is important to know the range of critical ecological processes and conditions that have characterized particular ecosystems over specified time periods and under varying degrees of human influences. Understanding the interactions of humans with natural variation in determining the current and future conditions of ecosystems is a primary goal of research that supports ecosystem management. The key premise in the application of HRV concepts to sustainable resource management is that knowledge

${ }^{1}$ Paper presented at "Mountain Forests: Conservation and Management," IUFRO Silviculture Conference, Vernon, British Columbia, Canada, July 28-August $1,2002$.

${ }^{2}$ Department of Geography, University of Colorado, Boulder, CO 80309-0260

USA. E-mail: veblen@spot.colorado.edu of how modern ecosystem structure has been influenced by natural and anthropogenic processes in the recent past provides context and guidance for managing mountain ecosystems today.

\section{Historic Range of Variability and Disturbance Ecology}

In the context of ecosystembased resource management there is an increased aware-

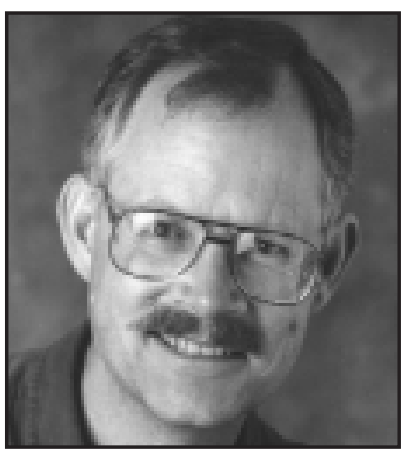

Thomas T. Veblen ness that ecosystems are not static and that sources of change include both humans and natural processes (Swanson et al. 1993, Morgan et al. 1994). The emphasis on the dynamic character of forested ecosystems in ecosystem management represents a major shift in attitudes over the past several decades among scientists and resource managers towards the concepts of change and instability in ecosystems (Pickett and White 1985). Formerly, there was a widespread expectation of a "balance of nature" that was reflected in concepts that stressed stability, such as the climax concept or homeostatic self-regulation of ecosystem properties (Botkin 1990). Today, ecosystem change is regarded as normal, and periods of relatively rapid versus slow change should be expected and accommodated in management practices. 
Understanding of the natural variability in ecosystem conditions and processes also provides operational flexibility for management actions and protocols (Landres et al. 1999). Incorporating historical ecosystem patterns into management goals provides a coarse-filter strategy for dealing with sustainability of diverse and often unknown species requirements. Managing within boundaries of site variability and history is also probably easier and less expensive to achieve than trying to manage outside of constraints imposed by driving factors of the system (Landres et al. 1999).

Ecological restoration is an increasingly important objective of forest management. Resource managers often seek to restore and maintain ecosystems by reinstating select characteristics of disturbance regimes (Kaufmann et al. 1994, Mast et al. 1998). The most reasonable templates for this restoration are descriptions of forest structure and composition and of disturbance regimes that existed prior to significant land-use changes brought on by Euro-American settlement. Although studies of historical range of variability often focus on the time of initial large-scale and permanent Euro-American settlement (typically the mid-19th century for much of western North America), ecosystem conditions were in flux prior to this time as well, probably due in part to impacts of Native Americans and certainly due to natural processes such as climatic variations or natural dispersal of species. Thus, the conditions that may be described for key dates such as settlement or the establishment of national forest reserves are only snapshots of changing landscapes. Consequently, for purposes of ecological restoration it is important to understand the nature and causes of this range of landscape characteristics.

Understanding the influences of humans on landscape patterns requires an appreciation of the roles of both natural and anthropogenic disturbances in vegetation dynamics (Oliver and Larson 1990). Disturbance has been defined as "any relatively discrete event in time that disrupts ecosystem, community, or population structure and changes resources, substrate availability, or the physical environment" (White and Picket 1985). Disturbances remove biomass that creates space for new individuals and releases resources to new and surviving ones. Historical legacies in vegetation patterns, established by spatial and temporal variability in disturbance occurrences, can persist for long periods until new vegetation patterns are restructured by either climate changes or subsequent intense disturbances.

A conceptual framework for analyzing the characteristics and consequences of disturbance is that of the disturbance regimeor the combination of spatial and temporal characteristics of disturbances in a particular landscape (Paine and Levin 1981, White and Pickett 1985). The key potential descriptors of a disturbance regime are: 1) spatial distribution; 2) frequency; 3) size of the area disturbed; 4) mean return interval; 5) predictability; 6) rotation period (time required to disturb an area equivalent to the study area once); 7) magnitude or severity; and 8) the synergistic interactions of different kinds of disturbances and their driving factors (e.g., climate, human ignition sources). Disturbance regimes must be examined for particular forest ecosystem types in particular locations in order to understand the HRV of the management unit. In other words, knowledge of disturbance regimes derived from studies conducted off site at best provides only an initial hypothesis that must be investigated with areaspecific research. In addition to being area-specific, studies of disturbance regimes need to consider shifts in disturbance patterns associated with relatively long-term climatic variation. For example, the parameters describing a fire regime may be relatively constant for a century or more but then change significantly due to centennial-scale climatic variation.

\section{Application: the 2002 fires in montane forests in northern Colorado}

The year 2002 was a year of widespread and severe fires in the montane forests of ponderosa pine and Douglas fir in the Colorado Front Range, which naturally has led to a debate over the role of past management practices (i.e., fire exclusion) on the extent and severity of fires in this region. A major premise underlying much current and proposed forest management in western North America is the idea that many decades of fire exclusion have resulted in fuel buildup that in turn is resulting in more extensive and more severe fires than would have occurred naturally. This viewpoint is derived primarily from studies of ponderosa pine in the Southwest U.S. (Covington and Moore 1994).

While this viewpoint is well supported by fire history and stand reconstruction studies in particular forest ecosystems, for other forest types and even other locations of the same forest type it is necessary to critically evaluate the applicability of this premise. This fire exclusion/fuel buildup perspective needs to be evaluated in relation to the 2002 fire year in Colorado when more area of montane forest burned than in any other year in the past 50 years.

In the northern Front Range of Colorado there are areas primarily at lower elevations and near ecotones with grasslands where fire scars indicate relatively frequent occurrence of non-lethal surface fires in ponderosa pine stands prior to the early 1900 s (i.e., many fire intervals $<20$ years at a spatial scale of about 100 ha; Veblen et al. 2000). Although Native Americans intentionally set fires in some habitats, modern records of the frequency of lightning-ignited fires suggest that even in the absence of anthropogenic ignitions a similar pattern of fire would have occurred (Veblen et al. 2000). Historical photographs and tree ages indicate that since the early 1900s there has been a substantial increase in tree densities in these ponderosa pine ecosystems (Veblen and Lorenz 1986, 1991; Mast et al. 1998). Thus, at lower elevations (and at mid-montane sites adjacent to grasslands) there are sites in the northern Front Range where conversion of formerly open woodlands to relatively dense stands of ponderosa pine are qualitatively similar to the pattern widely documented in Arizona (Moore et al. 1999). In such areas, the fire exclusion/fuel build up viewpoint is supported.

The challenge is to determine the spatial limits of this pattern of substantial increase in tree density following exclusion of formerly frequent surface fires. Towards higher elevation and at more mesic sites in the northern Front Range, a variety of evidence indicates that the historic fire regime was a mixedseverity regime including both stand-replacing and surface fires. In the northern Front Range in ponderosa pine forests, the pre1900 frequency of fire events inferred from fire scars declines dramatically with increasing elevation (Veblen et al. 2000). At the spatial scale of about 50 to 200 ha at elevations above 2100 $\mathrm{m}$ most fire intervals are well over 50 years in length, and there is no evidence of frequent (i.e., repeated intervals $<20$ years), widespread surface fires. In these stands with relatively long fire intervals and in the surrounding areas, the predominant age 
structure type is even-aged with most stands originating between the mid-1800s and early 1900s, but with remnants of older cohorts as well (Veblen and Lorenz 1986; Sherriff and Veblen unpublished data).

Historical photographs of the upper montane zone taken in the late 1800 s to early 1900 s show that large areas of ponderosa pine-dominated forests (typically with some component of Douglas-fir and other species) had burned in stand-replacing crown fires in the mid- to late-1800s prior to any significant fire exclusion or unnatural fuel buildup (Veblen and Lorenz 1991). Over most of the surface area of the ponderosa pine cover type in the northern Front Range, the pattern of dense stands due to recovery following $19^{\text {th }}$ century burning is much more common than the pattern of dense stands resulting from tree encroachment following cessation of frequent surface fires.

Knowledge of the HRV of fire and forest conditions in the montane zone of northern Colorado leads to the conclusion that the extensive and severe fires of 2002 cannot be generally attributed to fuel buildup during the fire exclusion period. Although at some sites (mainly at the lowest elevations) the 2002 fires were probably more severe due to fuels buildup (as inferred from the known fire history; Veblen et al. 2000), for the montane zone as a whole the 2002 fires were within the HRV of fire documented for the past 400 years or so in this region. The extent and severity of the 2002 fires is attributable primarily to extreme drought rather than to past management practices.

\section{Application: the late 1990s fires in northern Patagonia, Argentina}

In the Andes and foothills of Northern Patagonia (southwestern Argentina), during the summers of 1996-97 and 1998-99 unusually large areas of forest and shrub lands were burned in wildfires. These record fire years coincided with exceptionally dry springs, which at some climate stations were the driest of the past 90 years of record keeping (Veblen et al. 2002). The exceptional drought and fires motivated some key management questions: Were the fires of the late 1990s outside the historic range of variability in terms of extent or severity? What are the medium-term consequences of these fires in terms of vegetation composition and landscape structure? Retrospective studies of the historic range of variability of fire and forest ecosystems provide at least tentative answers to these questions that can inform management decisions and resource planning.

Tree-ring studies of fire history in Northern Patagonia clearly document previous years of very widespread fires in association with earlier droughts (Veblen et al. 1999). For example, tree-ring evidence documents widespread fires in northern Patagonia in 1827 coincident with a strong El Niño event, which results in hot summers in this region. These fires burned not only in the xeric shrub lands and woodlands, but also in the rain forests in remote areas of the Andes. Thus, the extent of the 1990s fires and the range of vegetation types included (from xeric shrub lands to tall rain forest) are not unique in comparison with the 400-year fire record.

Although the extent and severity of the late 1990s fires may not be outside their historic range of variability at a time scale of several centuries, the ecological impacts of these and other $20^{\text {th }}$ century fires may be resulting in a major shift towards an increasing area of shrub lands at the expense of tall forest (Veblen et al. 2002). Two major determinants of landscape structure changed during the $20^{\text {th }}$ century. First, the tree-ring evidence of climatic variation indicates that the $20^{\text {th }}$ century has included periods (from single years to several decades) that were warmer and drier than any other time during the past 400 years (Villalba et al. 1998). Secondly, since the late 1800s Euro-American settlers have had a significant impact on the landscape through intentional burning of forests and indirectly through the introduction of livestock and wild herbivores (deer, hares). Following the burning of tall forests in areas adjacent to shrub lands, there is an expansion of the area of shrub land due to the vigorous post-fire sprouting of all the shrub species. Furthermore, the shrub species are more browse-resistant than the tree species so that post-fire herbivore impacts tend to inhibit tree regeneration and favour dominance by shrubs.

The net effect of these human impacts (intentional burning and herbivory by introduced animals) has been a significant shift from forest to shrub land vegetation during periods of warmer and drier climate such as 1890 to the 1910s, the 1940s, and now the late 1990s. Shrub lands in this region are more flammable than tall forests so that this vegetation shift has a strong positive feedback resulting in increased fire occurrence. Consequently, the previous history of human impacts increases the likelihood of fire and accelerated conversion from forest to shrub land. In addition, the strong trend towards a warmer and drier climate in this region since the mid-1970s (Daniels and Veblen 2000) implies that tree regeneration in the near future will continue to be impeded.

\section{Conclusions}

Retrospective studies of disturbance ecology and climatic variation in the Colorado Rockies and the southern Andes illustrate how resource planning and management can benefit from knowledge of historic range of variability of these landscapes in at least four key ways:

1. Historical perspectives can reduce the chances of major future surprises and help us assess how exceptional extreme events may or may not be. For example, the long-term treering record of fire in the montane zone of the Colorado Front Range shows that pre-historic fires were as extensive and probably as severe during $19^{\text {th }}$ century and earlier droughts as they were in the 2002 fire season.

2. Climatic variation often overrides the influences of past and present management practices. For example, in the montane zone of Colorado extreme drought played a greater role in the widespread fires of 2002 than did fuels accumulation under several decades of fire exclusion.

3. Legacies from past disturbance events often have longlasting impacts on the landscape that shape future responses to disturbances and climatic variation. For example, in Northern Patagonia episodes of cutting and burning in the late $19^{\text {th }}$ and early $20^{\text {th }}$ centuries converted extensive areas of tall forest to more flammable shrub lands, thus creating a future positive feedback with fire.

4. Area-specific studies of historic range of variability allow managers to evaluate general models that often have only limited applicability outside the geographic areas and ecosystem types in which these models were originally developed. For example, the fire exclusion/fuels buildup model developed primarily from studies in the Southwest U.S. has only limited applicability to the forest ecosystems of northern Colorado. 


\section{References}

Botkin, D.B. 1990. Discordant harmonies: a new ecology for the twenty-first century. Oxford University Press. New York. 241 p.

Christensen, N.L., A.M. Bartuska, J.H. Brown, S. Carpenter, C. D. Antonio, R. Francis, J.F. Franklin, J.A. MacMahon, R.F. Noss, D.J. Parsons, C.H. Peterson, M.G. Turner and R.G. Woodmansee. 1996. The report of the Ecological Society of America committee on the scientific basis for ecosystem management. Ecological Applications 6: 665-691.

Covington, W.W., and M.M. Moore. 1994. Southwestern ponderosa forest structure: changes since Euro-American settlement. Journal of Forestry 92: 39-47.

Daniels, L.D. and T.T. Veblen. 2000. ENSO effects on temperature and precipitation of the Patagonian-Andean region: Implications for biogeography. Physical Geography 21: 223-243.

Kaufmann, M.R., R.T. Graham, D.A. Boyce, Jr., W.H. Moir, L. Perry, R.T. Reynolds, R.L. Bassett, P. Mehlhop, C.B. Edminster, W.M. Block and P.S. Corn. 1994. An ecological basis for ecosystem management. USDA Forest Service, General Technical Report RM-246.

Landres, P., P. Morgan and F. Swanson. 1999. Overview of the use of natural variability concepts in managing ecological systems. Ecological Applications 9: 1179-1188.

Mast, J.N., T.T. Veblen and Y.B. Linhart. 1998. Disturbance and climatic influences on age structure of ponderosa pine at the pine/grassland ecotone, Colorado Front Range. Journal of Biogeography 25: 743-767.

Moore, M.M., W.W. Covington and P.Z. Fule. 1999. Reference conditions and ecological restoration: a southwestern ponderosa pine perspective. Ecological Applications 9: 1266-1277.

Morgan, P., G.H. Aplet, J.B. Haufler, H.C. Humphries, M.M. Moore and W.D. Wilson. 1994. Historical range of variability: a useful tool for evaluating ecosystem change. Journal of Sustainable Forestry 2: 87-111.

Oliver, C.D. and B.C. Larson. 1990. Forest stand dynamics McGraw Hill, New York, New York.
Paine, R.T. and S.A. Levin. 1981. Intertidal landscapes: disturbance and the dynamics of pattern. Ecological Monographs 51: 145-178. Pickett, S.T.A. and P.S. White (eds.). 1985. The ecology of natural disturbance and patch dynamics. Academic Press, New York.

Swanson, F.J., J.A. Jones, D.O. Wallin and J.H. Cissel. 1993. Natural variability - implications for ecosystem management. In M.E. Jensen and P.S. Bourgeron (eds.). Ecosystem management: principles and applications, Volume II, Eastside Forest Health Assessment. pp. 89-103. USDA Forest Service, General Technical Report PNW-318.

Veblen, T.T., T. Kitzberger, R. Villalba and J. Donnegan. 1999. Fire history in northern Patagonia: The roles of humans and climatic variation. Ecological Monographs 69: 47-67.

Veblen, T.T., T. Kitzberger and J. Donnegan. 2000. Climatic and human influences on fire regimes in ponderosa pine forests in the Colorado Front Range. Ecological Applications 10: 1178-1195.

Veblen, T.T., T. Kitzberger, E. Raffaele and D.C. Lorenz. 2002. Fire history and vegetation change in northern Patagonia, Argentina. In T.T. Veblen, W.L. Baker, G. Montenegro and T.W. Swetnam (eds.). Fire Regimes and Climatic Change in Temperate Ecosystems of the Western Americas. pp. 259-289. Springer-Verlag.

Veblen, T.T. and D.C. Lorenz. 1986. Anthropogenic disturbance and recovery patterns in montane forests, Colorado Front Range. Physical Geography 7: 1-24.

Veblen, T.T. and D.C. Lorenz. 1991. The Colorado Front Range: a century of ecological change. University of Utah Press, Salt Lake City, Utah. 186 p.

Villalba, R. E.R. Cook, G.C. Jacoby, R.D. D’Arrigo, T.T. Veblen and P.D. Jones. 1998. Tree-ring based reconstructions of precipitation in Patagonia since A.D. 1600. Holocene 8: 659-674.

White, P.S. and S.T.A. Pickett. 1985. Natural disturbance and patch dynamics: an introduction. In S.T.A. Pickett and P.S. White (eds.). The ecology of natural disturbance and patch dynamics. pp. 3-13 Academic Press, Inc., Orlando, Florida. 472 p. 